\title{
Rapid, reliable and inexpensive quality assessment of biotinylated cRNA
}

T. Zander ${ }^{1,2}$,
J.A. Yunes
A.A. Cardoso
A.
and L.M. Nadler

\author{
'Department of Medical Oncology, Dana-Farber Cancer Institute, \\ Harvard Medical School, Boston, MA, USA \\ ${ }^{2}$ Molecular Tumor Biology and Tumor Immunology, \\ Center for Internal Medicine, University Cologne, Cologne, Germany \\ ${ }^{3}$ Centro Infantil Boldrini, Campinas, SP, Brasil
}

\footnotetext{
Correspondence

J.A. Yunes

Centro Infantil Boldrini

Rua Gabriel Porto, 1270

13083-210 Campinas, SP

Brasil

Fax: +55-19-3289-3571

E-mail: andres@boldrini.org.br

T. Zander was supported in part by the Frauke Weiskam-Christel Ruranski Foundation (Germany), and by grants from the NIH (PO1CA78378), and the Leukemia and Lymphoma Society (6447) to Joachim Schultze. J.A. Yunes and A.A. Cardoso were partially supported by a grant from NIH (PO1CA68484) and J.A. Yunes was partially supported by a grant from the Children's Leukemia Research Association (USA).
}

Publication supported by FAPESP. ........................

Received July 29, 2005 Accepted January 2, 2006

\begin{abstract}
The interpretation of oligonucleotide array experiments depends on the quality of the target cRNA used. cRNA target quality is assessed by quantitative analysis of the representation of 5' and 3' sequences of control genes using commercially available Test arrays. The Test array provides an economically priced means of determining the quality of labeled target prior to analysis on whole genome expression arrays. This manuscript validates the use of a duplex RT-PCR assay as a faster $(6 \mathrm{~h})$ and less expensive $(<\mathrm{US} \$ 10)$ but equally accurate alternative to the Test arrays in determining biotinylated cRNA quality. Forty-one different cRNA samples were hybridized to HG-U133A microarrays from Affymetrix. Ten cRNA samples with a B-actin 3'/5' ratio $>6$ were chosen and classified as degraded cRNAs, and 31 samples with a $B$-actin $3^{\prime} / 5^{\prime}$ ratio $<6$ were selected as good quality cRNAs. Blinded samples were then used for the RT-PCR assay. After gel electrophoresis, optical densities of the amplified 3 ' and 5' fragments of $B$-actin were measured and the $3^{\prime} / 5^{\prime}$ ratio was calculated. There was a strong correlation $\left(r^{2}=0.6802\right)$ between the array and the RT-PCR B-actin 3'/5' ratios. Moreover, the RT-PCR 3'/5' ratio was significantly different $(\mathrm{P}<0.0001)$ between undegraded (mean $\pm \mathrm{SD}$, $0.34 \pm 0.09)$ and degraded $(1.71 \pm 0.83)$ samples. None of the other parameters analyzed, such as i) the starting amount of RNA, ii) RNA quality assessed using the Bioanalyzer Chip technology, or iii) the concentration and OD260/OD280 ratio of the purified biotinylated cRNA, correlated with cRNA quality.
\end{abstract}

Key words

- Microarray

- Biotinylated cRNA

- Probe quality

- 5' Representation

- 3'/5' Ratio
Analysis of the transcriptome using highdensity oligonucleotide arrays is an important tool for discovery in biology (1). The preparation of the target cRNA is a multistep procedure that requires RNA isolation, first strand cDNA synthesis with an oligo(dT) primer bearing a $\mathrm{T} 7$ promoter, second-strand cDNA synthesis, and a final in vitro transcription using T7 RNA polymerase and bio- tinylated ribonucleotides. These enzymatic reactions are sensitive to the quality of the starting RNA, the intermediate cDNA template, the occurrence of endogenous priming, and the presence of impurities, such as RNases. Incomplete cDNA or cRNA synthesis usually results in 5' shortening of the target cRNA molecules (2), which is difficult to assess using gel-based assays. To 
overcome this obstacle, microarray's oligonucleotide probes are usually selected among the last 600 nucleotides of the mRNA end, and cRNA target quality is assessed by quantitative analysis of the representation of $5^{\prime}$ and 3' sequences of control genes, such as Bactin, GAPDH, ISGF3, RGE, or TFRR. For quality control, Test arrays containing probe sets corresponding to the $5^{\prime}$ and $3^{\prime}$ regions of selected genes are generally used (e.g., TEST3 Chip; Affymetrix, Santa Clara, CA, USA). Here, the main quality criterion is the $3^{\prime} / 5^{\prime}$ ratio. However, for $3^{\prime} / 5$ ' ratio analysis, array technology may not be the most effective method and can be replaced by other quantitative approaches. RT-PCR has been successfully applied for semi-quantification (3) and quantification of RNA templates (4), and in a multiplex setting (5). Its comparability to microarray data has been demonstrated $(6,7)$. Since no dramatic changes in expression values from sample to sample were observed (8) and degradation of different RNA species is similar and correlates with the overall RNA degradation (9), analysis of ubiquitous housekeeping genes is a valid surrogate for overall degradation and incomplete cDNA/cRNA synthesis. RT-PCR permitted the confirmation of the loss of 5' complexity in RNA subjected to autolysis (10). However, to our knowledge, no similar quality assessment of biotinylated cRNA by RT-PCR has been described. Here, we report a rapid, reliable and simple RT-PCR-based method for quality assessment of biotinylated cRNA.

cRNA was generated from total RNA from human blood mononuclear cells following standard protocols (11). The Institutional Review Board approved these studies and informed consent was obtained from donors. Hybridization, washing, staining, and scanning of HG-U133A Affymetrix arrays were performed according to the Affymetrix instructions. Target cRNA quality was assessed by calculating the $3^{\prime} / 5^{\prime}$ ratio value for the $\beta$-actin gene (interrogation probes:
AFFX-HSAC07/X00351_5_at and AFFXHSAC07/X00351_3_at). A 3'/5' ratio of 6 was defined as the cut-off value to discriminate the poor quality target cRNAs. From our existing database, 10 samples with a $3^{\prime} / 5^{\prime}$ ratio $>6$ were chosen and classified as degraded cRNAs, and 31 samples with a $3^{\prime} / 5^{\prime}$ ratio of $\beta$-actin $<6$ were selected as good quality cRNAs. Blinded samples were then used for the RT-PCR assay and the code was opened only after results were obtained and interpreted.

Primers were designed using the OLIGO 6.7 software (Molecular Biology Insights, Cascade, CO, USA): 204U, 5'-TGGTGGGC ATGGGTCAGA-3', and 453L, 5'-GTACA TGGCTGGGGTGTTGA-3' for the 5' B-actin region (269 bp), and 1260U, 5'-AAC AAGATGAGATTGGCA-3', and 1696L, 5'-GACCAAAAGCCTTCATACAT-3' for the 3 ' region (456 bp), as shown in Figure 1B. For the duplex RT-PCR analysis, $500 \mathrm{ng}$ of the biotinylated target cRNA (not fragmented) plus $1 \mu \mathrm{g}$ of random hexamers were denatured for $2 \mathrm{~min}$ at $70^{\circ} \mathrm{C}$ in a total volume of $12.5 \mu \mathrm{L}$, and then chilled on ice. Reverse transcription reactions were carried out in 20 $\mu \mathrm{L}$ containing $50 \mathrm{mM}$ Tris- $\mathrm{HCl}, \mathrm{pH} 8.3,75$ $\mathrm{mM} \mathrm{KCl}, 3.5 \mathrm{mM} \mathrm{MgCl} 2,0.5 \mathrm{mM}$ dNTPs, $20 \mathrm{U}$ recombinant RNase inhibitor (BD Bioscience Clontech, Palo Alto, CA, USA) and $200 \mathrm{U}$ MMLV reverse transcriptase (BD Bioscience Clontech) at $42^{\circ} \mathrm{C}$ for $1 \mathrm{~h}$ followed by 5 -min heating at $80^{\circ} \mathrm{C}$ to denature proteins. The cDNA thus obtained was diluted to a total volume of $100 \mu \mathrm{L}$ with $\mathrm{H}_{2} \mathrm{O}$ and $3 \mu \mathrm{L}$ was used for PCR. PCR was performed in $30 \mu \mathrm{L}$ containing $50 \mathrm{mM} \mathrm{KCl}, 10$ $\mathrm{mM}$ Tris-HCl, $\mathrm{pH} 8.3,3.5 \mathrm{mM} \mathrm{MgCl} 2,0.1 \%$ Triton X100, 0.2 mM dNTPs, 1 U Taq polymerase (Fisher Scientific, Pittsburgh, PA, USA), 5 pmol of each primer, in a GeneAmp 9600 thermocycler (Applied Biosystems, Foster City, CA, USA). The cycling protocol consisted of $10 \mathrm{~min}$ at $95^{\circ} \mathrm{C}$ for denaturation, followed by 6 cycles of annealing at decreasing temperatures from $65^{\circ}$ to $60^{\circ} \mathrm{C}$ 

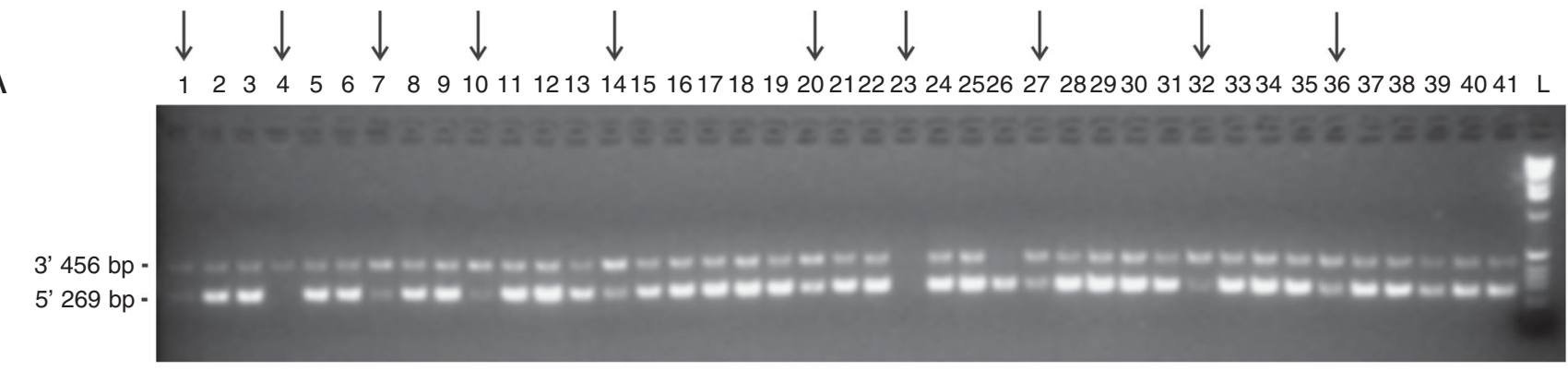

B
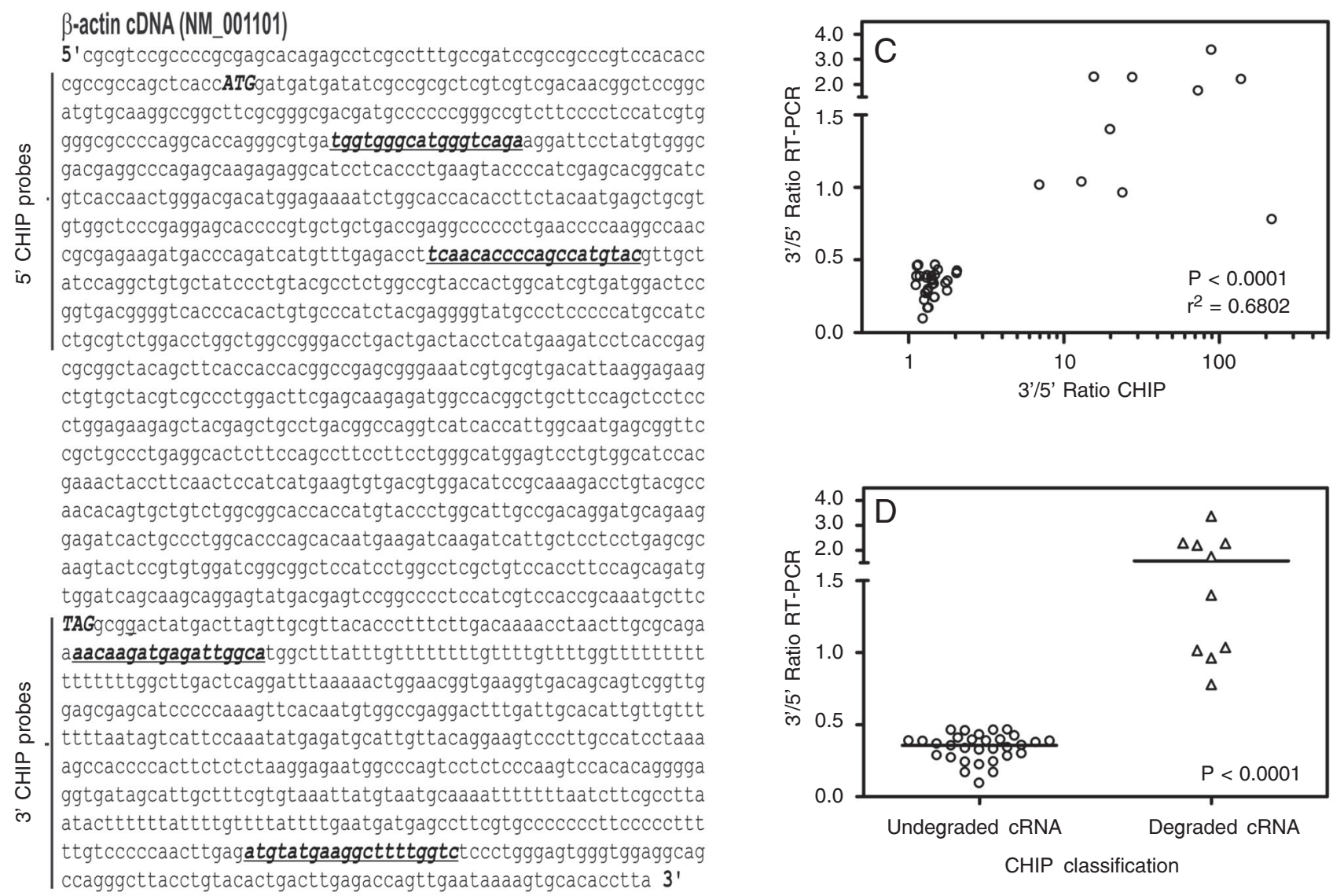

Figure 1. cRNA quality assessment by the analysis of B-actin 5' and 3' sequence abundance using a duplex RT-PCR in comparison to the microarrayobtained $3^{\prime} / 5$ ' ratio. A, RT-PCR products (sample 1 through 41 ) were analyzed on a $2 \%$ agarose gel stained with ethidium bromide. The 3 ' $B$-actin (456 bp) and the 5' B-actin (269 bp) PCR products were detected. L = $1 \mathrm{~Kb}$ DNA ladder (Invitrogen, Carlsbad, CA, USA). Arrows show samples classified as degraded by the microarray result. $B, B$-actin CDNA sequence. ATG and TGA correspond to the translation start and termination codons, respectively. Sequence regions targeted by the array 3' and 5' probes are depicted. Underlined sequences correspond to the location of primers used for PCR. C, The optical density of each band was measured and the $3^{\prime} / 5^{\prime}$ ratio was calculated and plotted against the respective $3^{\prime} / 5^{\prime}$ ratio assessed by the Affymetrix HG-U133A microarray (CHIP) analysis. CHIP 3'/5' ratios were transformed into logarithmic values for correlation analysis (Pearson test). $D$, The RT-PCR 3'/5'ratios of samples classified as undegraded (CHIP $3^{\prime} / 5^{\prime}$ ratio $<6$ ) and degraded $\left(\mathrm{CHIP} 3^{\prime} / 5^{\prime}\right.$ ratio $\left.>6\right)$ are shown. Significance was calculated using the Student $t$-test. 
$\left(1^{\circ} \mathrm{C}\right.$ decrease every cycle) for $45 \mathrm{~s}$, extension at $72^{\circ} \mathrm{C}$ for $45 \mathrm{~s}$ and denaturation at $95^{\circ} \mathrm{C}$ for $30 \mathrm{~s}$. Subsequently, 19 cycles were performed with annealing at $59^{\circ} \mathrm{C}$ for $45 \mathrm{~s}$, extension at $72^{\circ} \mathrm{C}$ for $45 \mathrm{~s}$, and denaturation at $95^{\circ} \mathrm{C}$ for $30 \mathrm{~s}$. A final extension step for 5 min at $72^{\circ} \mathrm{C}$ was included. Eight microliters of the PCR products was analyzed on a $2 \%$ agarose gel and visualized with ethidium bromide. For further semiquantitative analysis, densitometry was performed using the Kodak 1-D Image Analysis Software (Kodak, New Haven, CT, USA). The Student $t$-test and the Pearson correlation coefficient were applied to assess the significance of the results.

As described above, a duplex RT-PCR analysis was employed to amplify two PCR products corresponding to the $3^{\prime}$ and $5^{\prime}$ regions of $\beta$-actin, predicted as 456 and 269 $\mathrm{bp}$, respectively. The expected PCR products were detected in 40 of 41 target cRNA samples tested (Figure 1A). Sample 23 showed very weak amplification products even after several attempts. Since PCR conditions favor the amplification of the 5' $\mathrm{B}$ actin region, higher amounts of the 269-bp product were expected in cRNAs of the highest quality (e.g., samples 2, 3, and 26). A similar pattern was also observed for highquality total RNA (data not shown). By visual inspection, nine samples were clearly distinguished as having a higher amount of the $3^{\prime}$ region (456 bp) than the 5 ' region (269 bp) PCR product. Measurement of all bands by optical density and calculation of their $3^{\prime} /$ 5 ' ratios, resulted in their clustering into two distinct groups. Most importantly, there was a strong correlation $\left(r^{2}=0.6802\right)$ between the array (CHIP) and the RT-PCR B-actin 3'/ 5 ' ratios (Figure $1 \mathrm{C}$ ). As expected, all samples classified as degraded cRNAs by the array data were clustered into the RT-PCR higher ratio group. Furthermore, the 3'/5' ratio calculated by RT-PCR was significantly different $(P<0.0001)$ between the undegraded (mean $\pm \mathrm{SD}, 0.34 \pm 0.09$ ) and degraded $(1.71 \pm 0.83)$ group as defined by the array data (Figure 1D).

With the exception of one sample (sample 20), all other degraded samples had a $3^{\prime} / 5^{\prime}$ RT-PCR ratio above 0.95 . Sample 20 had a 3'/5' RT-PCR ratio of 0.78. All undegraded samples presented a 3'/5' RT-PCR ratio lower than 0.47. Therefore, an empirical cut-off point for the RT-PCR assay could be set at 0.65 .

As shown in Table 1, the quality of the cRNA obtained was not associated with the starting amount or quality of RNA used, as nearly all samples (except one; sample 23) were qualified as excellent using the Bioanalyzer Chip technology (Agilent, Palo Alto, CA, USA). Likewise, the concentration and

Table 1. Summary of the parameters tested to characterize biotinylated cRNA quality.

\begin{tabular}{lccccc}
\hline & $\begin{array}{c}\text { Starting } \\
\text { RNA }(\mu \mathrm{g})\end{array}$ & $\begin{array}{c}\text { Resulting } \\
\text { cRNA }(\mu \mathrm{g} / \mathrm{mL})\end{array}$ & $\begin{array}{c}\text { OD260/OD280 } \\
\text { cRNA }\end{array}$ & $\begin{array}{c}\text { 3'/5' ratio } \\
\text { microarray }\end{array}$ & $\begin{array}{c}\text { 3'/5' ratio } \\
\text { RT-PCR }\end{array}$ \\
\hline Degraded samples & $9.80 \pm 6.09$ & $904 \pm 404$ & $2.23 \pm 0.11$ & $62.73 \pm 69.33$ & $1.71 \pm 0.83$ \\
$(\mathrm{~N}=10)$ & 13.17 & 857 & 2.21 & 25.86 & 1.57 \\
& $(1.7-15)$ & $(440-1808)$ & $(2.12-2.42)$ & $(6.97-218)$ & $(0.78-3.37)$ \\
Undegraded samples & $9.95 \pm 4.51$ & $1272 \pm 487$ & $2.15 \pm 0.05$ & $1.43 \pm 0.24$ & $0.34 \pm 0.09$ \\
$(\mathrm{~N}=31)$ & 10.77 & 1199 & 2.14 & 1.41 & 0.36 \\
& $(0.03-15)$ & $(488-2584)$ & $(2.08-2.28)$ & $(1.12-2.06)$ & $(0.09-0.46)$ \\
\hline
\end{tabular}

Data are reported as means $\pm S D$ or as median with range in parentheses. Samples were classified as degraded $\left(3^{\prime} / 5^{\prime}\right.$ ratio $\left.>6\right)$ (bad quality) or undegraded $\left(3^{\prime} / 5^{\prime}\right.$ ratio $<6$ ) (good quality) using a threshold of 6 for the $3^{\prime} / 5$ ' ratio of $B$-actin on the oligonucleotide Affymetrix CHIP. The amount of starting material for cRNA synthesis reactions as well as the concentration and OD260/OD280 for the resulting cRNA are indicated. 
OD260/OD280 ratio of the purified biotinylated cRNA are not related to the quality of the cRNA. Finally, we could not assess the cRNA quality using gel-based systems since evaluation of smear shapes is very subjective (data not shown).

In summary, this fast, inexpensive and simple RT-PCR predicted the quality of the cRNA comparable to the $3^{\prime} / 5^{\prime}$ ratio of the Affymetrix test arrays. None of the other parameters analyzed correlated with the $3^{\prime} / 5^{\prime}$ ratio of the cRNA.

\section{Acknowledgments}

\section{We thank Dr. Edward Alwin Fox (Dana-}

Farber Cancer Institute, Boston, MA, USA) for numerous helpful discussions and for providing the cRNA samples.

\section{References}

1. Pomeroy SL, Tamayo P, Gaasenbeek M et al. (2002). Prediction of central nervous system embryonal tumour outcome based on gene expression. Nature, 415: 436-442.

2. Swift GH, Peyton MJ \& MacDonald RJ (2000). Assessment of RNA quality by semi-quantitative RT-PCR of multiple regions of a long ubiquitous mRNA. BioTechniques, 28: 524, 526, 528, 530-531.

3. Feldhahn N, Schwering I, Lee $S$ et al. (2002). Silencing of B cell receptor signals in human naive B cells. Journal of Experimental Medicine, 196: 1291-1305.

4. Roth CM (2002). Quantifying gene expression. Current Issues in Molecular Biology, 4: 93-100.

5. Burgess SC \& Davison TF (1999). A quantitative duplex PCR technique for measuring amounts of cell-associated Marek's disease virus: differences in two populations of lymphoma cells. Journal of Virological Methods, 82: 27-37.

6. Gnatenko DV, Dunn JJ, McCorkle SR et al. (2003). Transcript profiling of human platelets using microarray and serial analysis of gene expression. Blood, 101: 2285-2293.
7. Islam TC, Lindvall J, Wennborg A et al. (2002). Expression profiling in transformed human B cells: influence of Btk mutations and comparison to $\mathrm{B}$ cell lymphomas using filter and oligonucleotide arrays. European Journal of Immunology, 32: 982-993.

8. Warrington JA, Nair A, Mahadevappa M et al. (2000). Comparison of human adult and fetal expression and identification of 535 housekeeping/maintenance genes. Physiological Genomics, 2: 143-147.

9. Tong D, Schneeberger C, Leodolter S et al. (1997). Quantitative determination of gene expression by competitive reverse transcription-polymerase chain reaction in degraded RNA samples. Analytical Biochemistry, 251: 173-177.

10. Sugita M, Haney JL, Gemmill RM et al. (2001). One-step duplex reverse transcription-polymerase chain reaction for quantitative assessment of RNA degradation. Analytical Biochemistry, 295: 113116.

11. Golub TR, Slonim DK, Tamayo P et al. (1999). Molecular classification of cancer: class discovery and class prediction by gene expression monitoring. Science, 286: 531-537. 